\title{
1 Novel Paju Apodemus Paramyxovirus 1 and 2, Harbored by 2 Apodemus agrarius in The Republic of Korea
}

3

Seung-Ho Lee, ${ }^{\mathrm{a}}$ Jin Sun No, ${ }^{\mathrm{a},{ }^{*}}$ Kijin Kim, ${ }^{\mathrm{a}, *}$ Shailesh Budhathoki, ${ }^{\mathrm{b}}$ Kyungmin Park,,${ }^{\mathrm{a}, \mathrm{c}}$ Geum Young Lee, ${ }^{a}$ Seungchan Cho, ${ }^{a}$ Hyeok Sun Choi, ${ }^{d}$ Bong-Hyun Kim, ${ }^{\mathrm{e}}$ Seunghee Cho, ${ }^{\mathrm{e}}$ Jong Woo Kim, ${ }^{\mathrm{a}}$ Jin Gyeong Lee, ${ }^{\mathrm{a}}$ Seung Hye Cho, ${ }^{\mathrm{f}}$ Heung-Chul Kim, ${ }^{\mathrm{g}}$ Terry A. Klein, ${ }^{\mathrm{g}}$ Chang-Sub Uhm, ${ }^{\mathrm{h}}$ Won-Keun Kim, ${ }^{\mathrm{b}, \mathrm{d}, \#}$ Jin-Won Song ${ }^{\mathrm{a}, \mathrm{c}, \#}$

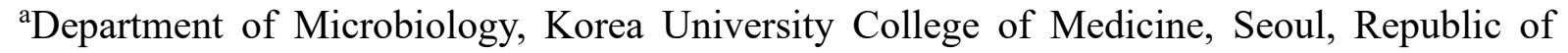
Korea

${ }^{b}$ Department of Microbiology, College of Medicine, Hallym University, Chuncheon, Republic of Korea

${ }^{\mathrm{c} B K} 21$ Graduate Program, Department of Biomedical Sciences, Korea University College of Medicine, Seoul, Republic of Korea

${ }^{\mathrm{d} I n s t i t u t e}$ of Medical Science, College of Medicine, Hallym University, Chuncheon, Republic of Korea

${ }^{\mathrm{e}}$ AAVATAR Therapeutics, Incheon, Republic of Korea

fDepartment of Biomedical Science, College of Natural Sciences, Hallym University, Chuncheon, Republic of Korea

${ }^{\mathrm{g}}$ Force Health Protection and Preventive Medicine, Medical Department Activity-Korea $/ 65^{\text {th }}$ Medical Brigade, Unit 15281, APO AP 96271-5281, USA

${ }^{\mathrm{h}}$ Department of Anatomy, Korea University College of Medicine, Seoul, Republic of Korea

Running Head: Identification of Novel Paramyxovirus in Rodent

\#Address correspondence to Jin-Won Song, jwsong@korea.ac.kr and Won-Keun Kim, wkkim1061@ hallym.ac.kr

*Present address: Division of High-risk Pathogens, Bureau of Infectious Diseases Diagnosis Control, Korea Disease Control and Prevention Agency, Cheongju 28159, Republic of Korea

${ }^{* *}$ Present address: Saarland University Saarbrücken Campus, Saarbrücken, Germany

Seung-Ho Lee and Jin Sun No contributed equally to this work. 


\section{Abstract}

Paramyxoviruses, negative-sense single-stranded RNA viruses, pose a potential threat to public health. Currently, 78 species and 17 genera of paramyxoviruses are classified and harbored by multiple natural reservoirs, including rodents, bats, birds, reptiles, and fish. Jeilongvirus has been proposed as a novel paramyxovirus genus containing J-, Beilong, and Tailam viruses, found in wild rodents. Using RT-PCR, 824 Apodemus agrarius individuals were examined for the prevalence of paramyxovirus infections. Paramyxovirus RNA was detected in $108(13.1 \%)$ rodents captured at 14 trapping sites in Korea. We first present two genetically distinct novel paramyxoviruses (genus Jeilongvirus), Paju Apodemus paramyxoviruses 1 (PAPV-1) and 2 (PAPV-2), from A. agrarius. Six PAPV strains were completely sequenced using nextgeneration and Sanger sequencing. PAPV-1 genome comprised 19,716 nucleotides, with eight genes (3'-N-P/V/C-M-F-SH-TM-G-L-5'), whereas PAPV-2 genome contained 17,475 nucleotides, with seven genes (3'-N-P/V/C-M-F-TM-G-L-5'). The disparity between PAPV-1 and -2 revealed the presence of the $S H$ gene and length of the $G$ gene in the genome organization. The phylogenies of PAPV-1 and -2 belong to distinct genetic lineages of Jeilongvirus despite being from the same natural host. PAPV-1 clustered with Beilong and Tailam viruses, while PAPV-2 formed a genetic lineage with Mount Mabu Lophuromys virus1. PAPV-1 infected human epithelial and endothelial cells, facilitating the induction of type I/III interferons, interferon-stimulated genes, and proinflammatory cytokines. Therefore, this study provides profound insights into the molecular epidemiology, virus-host interactions, and zoonotic potential of novel rodent-borne paramyxoviruses.

Importance

Paramyxoviruses are a critical public health and socio-economic burden to humans. Rodents play a crucial role in transmitting pathogens to humans. In the last decade, novel 
59 paramyxoviruses have been discovered in different rodents. Here, we found that Apodemus

60 agrarius harbored two distinct genotypes of the novel paramyxoviruses, Paju Apodemus

61 paramyxovirues 1 (PAPV-1) and $2(\mathrm{PAPV}-2)$, possessing unique genome structures that are

62 responsible for encoding TM and G proteins of different sizes. In addition, PAPV-1 infected

63 human epithelial and endothelial cells, facilitating the induction of type I/III IFNs, ISGs, and

64 proinflammatory cytokines. Thus, this study provides significant insights into molecular

65 prevalence, virus-host interactions of paramyxoviruses. These observations raise the awareness

66 of physicians and scientists about the emergence of new rodent-borne paramyxoviruses.

67

68 Keywords (Maximum 6): Rodent paramyxovirus, Apodemus agrarius, Paju Apodemus

69 paramyxovirus 1, Paju Apodemus paramyxovirus 2, phylogenetic diversity 


\section{Introduction}

71

Zoonotic diseases, transmitted from reservoir hosts to humans, comprise the majority of emerging and re-emerging infectious diseases and are public health and socio-economic threats (1-3). Emerging outbreaks of zoonotic viruses, such as severe acute respiratory syndrome coronavirus 2 , have increased recently because of expanding human activities that have enabled virus spillover, particularly in situations that facilitate close contact among diverse wildlife species, domesticated animals, and humans (4). Rodents serve as potential mammalian hosts and pose the highest risk of harboring zoonotic viruses to date (3). These animals cause significant economic losses in agriculture and transmit infectious agents including viruses, bacteria, and parasites that cause hemorrhagic fever, tsutsugamushi disease, and leptospirosis $(5,6)$. Among the rodents in Asia and Europe, Apodemus species is a natural reservoir host carrying pathogens that are detrimental to humans, and A. agrarius is widely distributed in various natural environments (e.g., rural areas, agricultural fields, and forests). Metagenomic studies and continuous surveillance of potential viruses in small mammals provided clues for preventive and mitigative strategies against new emerging and re-emerging infectious diseases $(7-12)$.

Paramyxoviruses are non-segmented, negative-sense single-stranded RNA viruses. Paramyxoviridae is divided into four subfamilies: Avulavirinae, Rubularvirinae, Metaparamyxovirinae, and Orthoparamyxovirinae. Orthoparamyxovirinae is classified into nine genera: Respirovirus, Aquaparamyxovirus, Fetavirus, Henipavirus, Jeilongvirus, Narmovirus, Salemvirus, Sunshinevirus, and Morbillivirus (13). Paramyxoviruses have a wide host range, including vertebrates (mammals, birds, reptiles, and fish) (14). Some paramyxoviruses, for example, human parainfluenza, Hendra, Nipah (NiV), mumps, and measles viruses, pose critical public health and socio-economic burdens owing to their pathogenicity in humans. 
The newly established genus Jeilongvirus has been identified in all rodents, and it consists of seven recognized species, J-virus (JV) (15), Beilong virus (BeiV) (16), Tailam virus (TaiV) (17), Mount Mabu Lophuromys virus 1 (MMLV-1) and 2 (MMLV-2), Shaan virus, and Pohorje Myodes paramyxovirus 1 (PMPV-1) (18). In 1972, JV was isolated from the kidney autoculture of a moribund house mouse (Mus musculus) captured in northern Queensland, Australia (19). BeiV was first identified in a human mesangial cell line (16). In 2012, the presence of BeiV was confirmed in the kidney and spleen tissues of brown (Rattus norvegicus) and black (Rattus rattus) rats in Hong Kong (20). TaiV was isolated from the kidney and spleen tissues of Sikkim rats (Rattus andamanensis) at the Tai Lam country park in Hong Kong (17). MMLV-1 and -2 were discovered in the kidney of a Rungwe brush-furred rat (Lophuromys machangui) in Mozambique, and PMPV-1 was found in the kidney of a bank vole (Myodes glareolus) in Slovenia (18). These viruses possess two additional transcription units encoding the small hydrophobic (SH) and transmembrane (TM) proteins between the fusion (F) and receptor binding protein genes, with the exception of MMLV-1 and -2, which contain the TM gene but not the $S H$ gene. In a previous study, paramyxovirus $\mathrm{SH}$ proteins were found to modulate the in vitro expressions of proinflammatory cytokines interleukin 6 (IL-6) and IL-8 via nuclear factor- $\kappa \mathrm{B}(\mathrm{NF}-\kappa \beta)$ activation (21). In particular, the SH protein of JV inhibited tumor necrosis factor- $\alpha$ (TNF- $\alpha)$ production and apoptosis in vitro and in vivo (22-24). However, the pathogenicity of these Jeilongviruses remains unexplored in humans.

In this study, 824 A. agrarius individuals were collected at 14 trapping sites and investigated for the prevalence, phylogenetic diversity, and genomic characterization of novel Paju Apodemus paramyxoviruses (PAPVs), PAPV-1 and -2, in the Republic of Korea (ROK).

PAPV-1 infected human cells and induced the expression of type I/III interferons (IFNs), interferon-stimulated genes (ISGs), and proinflammatory cytokines. Thus, this study provides 
119 significant insights into the genetic diversity, evolutionary dynamics, and virus-host

120 interactions of novel rodent-borne paramyxoviruses.

\section{Results}

\section{Molecular screening and isolation of PAPVs in rodents}

124 A total of 824 A. agrarius individuals were captured in various regions of the ROK from 2016 to 2018 (Figure S1). Paramyxovirus RNA was detected in 81/824 (9.8\%) A. agrarius individuals using specific primers targeting the genera Respirovirus, Morbillivirus, and Henipavirus $(14,287-14,725$ nt). Viral RNA was detected in 59/824 (7.2\%) rodents via RT-

128 PCR by targeting pan-Orthoparamyxovirinae (15,369-15,898 nt) (Table S1). In total, 108

129 (13.1\%) A. agrarius individuals were positive for paramyxovirus (Table 1). The prevalence of PAPV-1 was 87/824 (10.6\%), whereas that of PAPV-2 was 21/824 (2.6\%) $(P<0.001$ in Fisher's exact test). The geographic prevalence of PAPV was as follows: 39/361 (10.8\%) in Gangwon Province, 63/434 (14.5\%) in Gyeonggi Province, 1/6 (16.7\%) in Gyeongsangnam Province, and 5/23 (21.7\%) in Chungcheongnam Province (Table S2). The rodent-borne paramyxovirus,

134 PAPV, was first identified in A. agrarius captured in Paju, ROK. Among 370 male and 453 female A. agrarius, $56(15.1 \%)$ and $52(11.5 \%)$ harbored PAPV, respectively, indicating the gender-specific prevalence of this virus. Adult and old A. agrarius (20-30 g and 31-40 g, respectively) showed PAPV infection rates of 18.1\% (45 animals) and 22.4\% (34 animals),

138 respectively, whereas the juvenile and subadult animals $(<20.0 \mathrm{~g})$ showed low PAPV infection

139 rates (6.7\% and $4.5 \%$, respectively). PAPV-positive rodents were found in spring, summer, 140 autumn, and winter.

141 A. agrarius-borne paramyxovirus was isolated from the kidney tissues of Aa17-179 and Aa17-

142297 using a cell culture-based method. The paramyxovirus isolates from the infected rodents

143 showed a cytopathic effect of syncytia formation (not shown) in Vero E6 cells. The first isolate 
144 of PAPV-1 was confirmed by passaging two times for 14 days post-inoculation. The particles

145 of PAPV-1 were observed using a transmission electron microscope (Figure 1A). In addition,

146 the number of infectious PAPV particles was $3 \times 10^{5} \mathrm{PFU} / \mathrm{mL}$, quantified using the plaque assay

147 (Figure 1B).

148 Whole-genome sequencing of PAPVs using next generation sequencing (NGS) and rapid 149 amplification of cDNA ends (RACE) PCR

150 To obtain whole-genome sequences of PAPV, sequence-independent, single-primer 151 amplification-based MiSeq of the Aa17-179 and Aa17-297 isolates generated eight contigs 152 (520-976 nt in length) with significant similarities to the genomic sequence of 153 paramyxoviruses. The NGS of Aa17-179 and Aa17-297 generated 1,623,052 and 1,479,714 154 viral reads, respectively, and the depth of the viral genome sequence was 144,317 and 79,344, respectively (Table S3). The nearly complete genome sequences of four PAPV strains (Aa17255, Aa17-260, Aa17-154, and Aa17-166) were acquired via Illumina sequencing. Both the 3' and $5^{\prime}$ end sequences of the viral genomes revealed incomplete complementary sequences with

158 differences at nucleotide residues 4, 5, and 12. The genomic sequences of PAPV-1 and -2 have 159 been deposited in GenBank (Accession number: MT823459-MT823464).

160 Genomic organization of PAPVs

161 The whole genomes of PAPV-1 and -2 were 19,716 and 17,475 nt in length, with GC contents 162 of $39.96-40.09 \%$ and $37.34 \%$, respectively. PAPV-1 contained a genome structure composed 163 of eight genes in the order of $3^{\prime}-\mathrm{N}-\mathrm{P} / \mathrm{V} / \mathrm{C}-\mathrm{M}-\mathrm{F}-\mathrm{SH}-\mathrm{TM}-\mathrm{G}-\mathrm{L}-5^{\prime}$, while the genome structure of 164 PAPV-2 comprised seven genes in the order of $3^{\prime}-\mathrm{N}-\mathrm{P} / \mathrm{V} / \mathrm{C}-\mathrm{M}-\mathrm{F}-\mathrm{TM}-\mathrm{G}-\mathrm{L}-5^{\prime}$ (Figure 2). The $165 \mathrm{~N}, \mathrm{M}, \mathrm{F}, \mathrm{G}$, and $\mathrm{L}$ genes encode one protein, while the $\mathrm{P}$ gene, in addition to the viral 166 phosphoprotein, encodes some accessory proteins that arise through leaky scanning (C protein) 167 or RNA editing (V/W protein). This RNA editing occurs through the addition of one or more 168 guanine residues during transcription, following the recognition of a conserved RNA editing 
BeiV, and other rodent paramyxoviruses. PAPV-1 showed additional open reading frames

173 between the $\mathrm{F}$ and $\mathrm{G}$ genes, encoding an SH and/or TM protein. In contrast, PAPV-2 showed

174 the $T M$ gene but not the $S H$ gene. The $3^{\prime}$ leader and $5^{\prime}$ trailer sequences were 55 and 28 nt in length, respectively. The gene start, stop, and intergenic region sequences of PAPVs are shown in the Table S4.

\section{Phylogenetic analysis of the novel PAPV strains}

178 Phylogenetic inference of the whole-genome sequences of PAPVs demonstrated two distinct 179 genotypes within Jeilongviruses (Figure 3). The genetic cluster of PAPV-1 showed a high similarity (63.7-63.8\%) with TaiV, while the PAPV-2 group shared a common ancestor with MMLV-1, with a genomic similarity of $71.6 \%$ (Table S5). In addition, the amino acid sequences of the individual coding proteins of PAPV-1 and -2 constituted comparable phylogenetic patterns with the viral RNA genome sequences (Figure S2). The partial L genomic sequences $(14,287-14,725 \mathrm{nt})$ of novel PAPV strains phylogenetically belong to the genus Jeilongvirus, subfamily Orthoparamyxovirinae. Consistently, the phylogenies of PAPV closely related to TaiV, BeiV, and PMPV-1, whereas the PAPV-2 strains showed an

188 independent genetic clustering with MMLV-1. The partial L gene sequences of PAPV-1 were 189 differentiated into four genetic lineages (Figure S3). The genetic lineage I of PAPV-1 190 originated geographically in Dongducheon, Paju, Pocheon, and Yeoncheon in Gyeonggi

191 Province and Cheorwon in Gangwon Province. The genetic lineage II contained PAPV-1 192 strains in Pocheon in Gyeonggi Province, Chuncheon in Gangwon Province, and Taean and

193 Seosan in Chungcheongnam Province. Additionally, genetic lineage III was found in 
194 Dongducheon and Paju in Gyeonggi Province, and in Hwacheon and Yanggu in Gangwon

195 Province. A distinct strain from Changnyeong in Gyeongsangnam Province belonged to the

196 genetic lineage IV. Further, the partial L gene sequences of PAPV-2 showed two phylogenetic

197 clusters. Genetic lineage I included PAPV-2 in Yeoncheon, Paju, and Dongducheon, while

198 genetic lineage II of PAPV-2 was observed in only Yeoncheon, Gyeonggi Province.

\section{Analysis of N-linked glycosylation (NLG) in the G protein of Jeilongvirus}

200 To identify the glycosylation patterns of PAPV G proteins, potential NLG sites in the whole 201 amino acid sequences were predicted using NetNglyc 1.0 (Figure S4). PAPV-1 contains 24 202 NLGs in G proteins; 16/24 NLGs were potentially found at positions 56, 136, 175, 581, 770, $805,879,925,975,985,988,994,1,052,1,070,1,333$, and 1,576 over the threshold value $(0.5)$.

The ten potential NLG sites from PAPV-2 were estimated, and six of the potential NLGs had significant values at positions $48,355,587,620,716$, and 741 . Additionally, the glycosylation pattern of PAPV-1 appeared similar to that of PMPV-1, while the G protein of PAPV-2 was glycosylated less frequently with respect to that of MMLV-1, BeiV, and JV.

\section{Domain structural analysis of PAPV-1 and -2 G proteins}

209 The primary sequences of PAPV -1 and $-2 \mathrm{G}$ proteins are quite different in their lengths. The $\mathrm{G}$ protein of PAPV-1 consists of approximately 1,600 amino acids, whereas that of PAPV-2

211 consists of approximately 700 amino acids. The discrepancy between the two G proteins shows

212 the differential components in the domain diagram (Figure S5). The PAPV-1 G protein 213 contains $\mathrm{NH}(1-700$ aa) and $\beta$-strand (1,200-1,600 aa) domains linked by a natively long 214 disordered (DR) region (700-1,200 aa). In contrast, the PAPV-2 G protein has only the NH 215 domain based on protein homology search and secondary structure predictions. Structure 216 prediction and homology modelling indicated that the NH domains in both viruses were largely

217 similar in their protein architecture. Notably, both PAPV-1 and -2 G proteins have a single TM 218 domain in the NH domain. This indicates that the two additional domains in PAPV-1 G protein, 
219 DR and $\beta$-strand domains, compared to those in PAPV-2 G protein, are most likely expressed 220 as extracellular domains that may interact with host receptor proteins.

221 Induction of type I/III IFN, ISGs, and proinflammatory cytokines of PAPV-1 in human epithelial and endothelial cells

223 PAPV-1 was successfully isolated from Vero E6 cells. To determine the infectivity and induction of antiviral genes in human epithelial and endothelial cells, A549 and HUVEC were infected with PAPV-1, respectively, during 1, 3, 5, and 7 days (Figures 4 and 5). The replication of PAPV-1 gradually increased at 1, 3, 5, and 7 days post-infection(dpi). The mRNA of Ifn $\beta$, ISG15, Ifit2/Isg54, and Ifit1/Isg56 was upregulated by PAPV-1 infection at 3, 5, and $7 \mathrm{dpi}$, while Ifnll/Il-29 was slightly induced at $7 \mathrm{dpi}$. The expression of the antiviral genes Rsad2/Viperin and OAS1 increased during PAPV-1 infection, and the cytosolic sensors Ddx58/Rig-I and Ifih1/Mda5 were upregulated at 3, 5, and 7 dpi. In addition, the induction of Il-6 mRNA was observed in A549 and HUVEC at 3, 5, and 7 dpi. These results demonstrated that PAPV-1 indeed infected human epithelial and endothelial cells and induced the expression of innate antiviral genes including type I/III IFNs, ISGs, and proinflammatory cytokines.

Discussion

Here, we discovered and characterized two novel paramyxoviruses from A. agrarius (the striped field mouse) in the ROK. Whole-genome sequences of the paramyxoviruses were obtained using a combination of high-throughput and Sanger sequencing. The phylogenies of

239 PAPV-1 and -2 demonstrated that these two viruses represent distinct genetic lineages within the genus Jeilongvirus and family Paramyxoviridae. The genome organization (3'-N-P/V/C-

241 M-F-SH-TM-G-L-5') of these viruses was consistent with that of JV, BeiV, TaiV, and other

242 rodent paramyxoviruses. The genomic characteristics and nucleotide length $(19,716 \mathrm{nt})$ of the

243 PAPV-1 genome are similar to those of PMPV-1, the largest group of rodent-borne 
paramyxovirues reported to date. This is attributed to the presence of $S H$ and $T M$ genes and the large size of the $G$ gene. Additionally, the complete genome of PAPV-2 was 17,475 nt long, approximately $2 \mathrm{~kb}$ shorter than that of PAPV-1, owing to the lack of the $S H$ and $T M$ genes. According to the paramyxovirus species distinctive criterion (an amino acid distance of $>7-$ $7.5 \%$ in the L gene) (25), PAPV-1 and -2 were found to be sufficiently divergent to establish the new genus Jeilongvirus. These viruses have been suggested to constitute a separate genus within the family Paramyxoviridae (genus Jeilongvirus) based on their unique characteristics and evolutionary distance from other paramyxoviruses.

Recently, the host sharing of genetically distinct paramyxoviruses has been reported in nature $(18,26)$. MMLPV-1 and -2 co-infected in a kidney of a Rungwe brush-furred rat. The bank vole harbored PMPV-1 and bank vole virus (BaVV) in lung and kidney tissues. In this study, PAPV-1 and -2 were first discovered in the same host species, A. agrarius although they shared minimal similarity (nucleotide identities of 24.6-24.7\%). Notably, paramyxoviruses shared a natural reservoir host with the virus strain belonged to the same family but a significantly distinct phylogenetic lineage, such as PAPV-1 and -2 in A. agrarius, MMLPV-1 and -2 in $L$. machangui, and PMPV-1 and BaVV in M. glareolus, respectively. These observations arise plausible hypotheses: 1) The virus may be evolved and emerged as a distinctive virus strain via genetic addition or deletion on its progenitor genome. 2) Two naturally distinct viruses might coexist in the same host, followed by competition or cooperation with each other. However,

263 the preferential or predominant emergence of two distinct genotypes of rodent-borne 264 paramyxoviruses awaits further investigation.

265 Genomic characteristics of paramyxoviruses affect pathogenicity and evolution within hosts (27). Moreover, the molecular prevalence of PAPV-1 was found to be higher than that of PAPV-2. These results led us to hypothesize that the different genome compositions of PAPV- 
269 pathogenicity by affecting the host immune response and membrane fusion mechanism (21-

270 23). The SH protein found in paramyxoviruses, human metapneumovirus (HMPV), and JV 271 modulates TNF- $\alpha$ production and blocks apoptosis in vitro and in vivo. Deficient SH expression 272 enhances the secretion of proinflammatory cytokines IL-6 and IL-8 compared with that of the 273 wild-type HMPV. The SH protein of HMPV also increases membrane permeability and fusion 274 for viral entry (28). Intriguingly, PAPV-1 was found to possess the $S H$ gene, while PAPV-2 showed the absence of the gene. The presence of the $S H$ gene may be correlated with the higher prevalence of PAPV-1 (10.6\%) in natural hosts compared with that of PAPV-2 (2.6\%), since the antagonistic function or increased viral entry promotes propagation in infected cells.

278 Second, the G protein of paramyxoviruses is a predominant determinant of host specificity 279 because it promotes cell entry by interacting with specific proteins on the surface of target cells 280 (29, 30). Different paramyxovirus G proteins have evolved to allow optimal interaction and fusion with target cells in their respective hosts (31-36). The PAPV-1 G protein (1,602 amino acids) was shown to be considerably larger than the PAPV-2 G protein ( 826 amino acids). The G protein of PAPV-1 consists of the NH, DR, and $\beta$-strand domains, while the short length of the PAPV-2 G protein excludes the DR region. Intrinsically, disordered proteins may offer high flexibility to viral proteins either in the wholly or partially disordered form (37). The disordered protein of Zika virus conferred the capability for quick adaption in a changing environment, survival in host body environments, and invasion of the host defence mechanism (38). The characteristics of the DR region of the G protein may influence the higher prevalence of PAPV-1 compared to that of PAPV-2 in nature. Third, the NLG of G protein plays a role in protecting against neutralizing antibodies during cell-cell fusion and viral entry (39). The point mutation of potential NLG sites demonstrated that specific N-glycans in the NiV-G protein are significantly involved in viral entry. NLG in HIV-1 has been associated with survival and immune evasion, such as alteration of sensitivity to neutralizing antibody or reduction of 
sensitivity to serum antibody (40-42). In the case of NiV, NLG is involved in the proper functioning of proteins and life cycle by having a dual role including enhancement of resistance to antibody neutralization and/or alternative reduction in membrane fusion and viral entry (43). Based on NLG prediction, the G protein of PAPV-1 was found to contain more potential glycosylation sites than that of PAPV-2. Although its precise function is still unclear, the potential glycosylation sites of this protein are thought to aid in shielding the protein from recognition by the host immune system. Thus, the biological consequences of the $S H$ gene and molecular characteristics of G protein in PAPV-1 and -2 remain unexplored.

Infectivity and expression of innate antiviral genes significantly influence the pathological effects of viral infection in humans and mice (44-46). Due to the isolation of infectious particles,

304 PAPV-1 was examined for infectivity and induction of innate antiviral genes using human epithelial and endothelial cells. We found that the replication of PAPV-1 increased at 1, 3, 5, and 7 dpi in A549 and HUVEC, respectively. The expression of type I/III IFNs, ISGs, and proinflammatory cytokines were also upregulated in response to PAPV-1. These observations suggest that PAPV-1 may infect and elicit proinflammatory responses in humans. In this study,

309 PAPV-2 was not evaluated owing to the lack of infectious particles. The absence of the PAPV-

3102 SH gene might be involved in the robust induction of antiviral genes including type I IFNs

311 and cytokines, and this might be responsible for the failure to isolate infectious PAPV-2

312 particles. The comparisons of infectivity, immunogenicity, and pathogenesis between PAPV-

3131 and -2 remain to be investigated.

314 In conclusion, we presented two novel paramyxoviruses, PAPV-1 and -2, found in A. agrarius 315 in the ROK. These viruses were identified as new Jeilongviruses within the family

316 Paramyxoviridae using phylogenetic inference and genomic comparison with the nucleotide 317 and protein sequences of all currently known paramyxovirus species. A total of 102 partial 318 PAPV sequences (83 PAPV-1 and 19 PAPV-2) and six whole genome sequences (four PAPV- 
3191 and two PAPV-2) demonstrated the phylogenetic distribution and relationship of the novel 320 paramyxoviruses in the ROK. PAPV-1 infected human cells and induced the expression of 321 innate antiviral genes. Thus, this study provides profound insights into the molecular 322 prevalence, virus-host interactions, and zoonotic potential of rodent-borne paramyxoviruses.

323 Thus, these observations are expected to raise the awareness of physicians and scientists about 324 the emergence of novel PAPV-1 and -2.

\section{Materials and Methods}

\section{Ethics statement}

328 The animal trapping procedure was approved by the US Forces Korea (USFK) in accordance with USFK Regulation 40-1 "Prevention, Surveillance, and Treatment of Hemorrhagic Fever with Renal Syndrome.” All procedures and handling of animals were conducted according to the protocol approved by the Korea University Institutional Animal Care and Use Committee (KUIACUC, \#2016-0049).

\section{Animal trapping and PAPVs analyses}

334 Small mammals were captured from 2016 to 2018 using Sherman traps $(8 \times 9 \times 23 \mathrm{~cm}$; H. B.

335 Sherman, Tallahassee, FL, USA). The trapping sites were located in Cheorwon, Chuncheon, 336 Hongcheon, Hwacheon, Inje, Pyeongchang, and Yanggu in Gangwon Province; Dongducheon, 337 Paju, Pocheon, Suwon, Uijeongbu, and Yeoncheon in Gyeonggi Province; Seosan and Taean 338 in Chungcheongnam Province; and Changnyeong in Gyeongsangnam Province. The traps were 339 set at intervals of 1-2 $\mathrm{m}$ and examined early the next morning over a period of 1-2 days. Live 340 animals were humanely killed through cardiac puncture under alfaxalone-xylazine anaesthesia 341 and identified to the species level using morphological criteria and PCR when required. A total 342 of 913 rodent species, including 824 A. agrarius, 7 A. peninsulae, 10 M. musculus, 5 Micromys 343 minutus, 58 Myodes regulus, 9 Tscherskia triton, and 158 shrew species were captured. Serum, 
344 brain, lung, spleen, kidney, and liver tissues were collected aseptically and frozen at $-80^{\circ} \mathrm{C}$

345 until use.

\section{Cell lines}

347 Vero E6 cells (ATCC, \#DR-L2785), human lung adenocarcinoma cells (A549) (ATCC, \#CCL-

348 185), and human umbilical vein endothelial cells (HUVEC) (ATCC, \#CRL1730) were

349 purchased from ATCC. Vero E6, A549, and HUVEC were cultured in DMEM supplemented

350 with Dulbecco's modified Eagle's medium (DMEM), 10\% fetal bovine serum, $1 \mathrm{mM}$ sodium

351 pyruvate, $2 \mathrm{~mL}$ L-glutamine, and $50 \mathrm{mg} / \mathrm{ml}$ gentamicin. The cultures were incubated at $37^{\circ} \mathrm{C}$

352 in a $5 \% \mathrm{CO}_{2}$ incubator until use.

\section{Virus isolation}

354 Kidney tissues were ground in DMEM containing 5\% fetal bovine serum. After centrifugation, the supernatant was inoculated into Vero E6 cells. After one and a half hours of adsorption, the excess inoculum was discarded, and the mixture was replaced with $5.5 \mathrm{~mL}$ of DMEM. The cultures were incubated at $37^{\circ} \mathrm{C}$ in a $5 \% \mathrm{CO}_{2}$ incubator and inspected daily for cytopathic effects using inverted microscopy.

\section{In vitro infection}

360 A total of $1 \times 10^{6}$ cells per well were prepared in a 6-well plate. After $24 \mathrm{~h}$, the cells were infected with PAPV-1 at a multiplicity of infection of 0.02 . The samples were then collected at $1,3,5$, and 7 days post-infection. Detailed regarding cell lines are available in the supplementary

363 method 4.

\section{Plaque assay}

365 Vero E6 cells were seeded onto 6-well plates at a density of $1.5 \times 10^{6}$ cells per well. After overnight incubation at $37^{\circ} \mathrm{C}$, the monolayer was washed twice with PBS and inoculated with 10-fold serially diluted viruses. After $90 \mathrm{~min}$ of incubation at $37^{\circ} \mathrm{C}$ with constant shaking, the monolayer was overlaid with a 1:1 overlay medium and medium-melting-point agarose mix. 
369 Additionally, following incubation at $37^{\circ} \mathrm{C}$ for 5 days, the agarose overlay was discarded. The 370 plaques were visualized by staining the monolayer with $0.1 \%$ crystal violet in $10 \%$

371 formaldehyde.

\section{Electron microscopy}

373 Paramyxovirus-infected Vero E6 cells were collected at 7 days post-infection and fixed with $3742 \%$ paraformaldehyde and $2.5 \%$ glutaraldehyde with $0.1 \mathrm{M}$ phosphate buffer, $\mathrm{pH}$ 7.4. Thin sections were placed onto 400-mesh square copper electron microscopy grids (Electron Microscopy Sciences) and viewed under a transmission electron microscope (Model H-7650;

377 Hitachi, Japan).

\section{RNA extraction and RT-PCR}

379 Total RNA was extracted from the lung and kidney tissues of rodents using TRI Reagent 380 Solution (AMBION Inc., Austin, Texas, USA). cDNA was synthesized using a high capacity 381 RNA-to-cDNA kit (Applied Biosystems, Foster City, CA, USA). First, nested PCRs were 382 performed in a $25-\mu \mathrm{L}$ reaction mixture containing $2.5 \mathrm{U}$ of Ex Taq DNA polymerase (TaKaRa 383 BIO Inc., Shiga, Japan), $2 \mu \mathrm{g}$ of cDNA, and $10 \mathrm{pM}$ of each primer. The oligonucleotide primer 384 sequences for the nested PCR were PAR-F (outer): 5'-ATG TAY GTB AGT GCW GAT GC3', PAR-R1 (outer): 5'-AAC CAD TCW GTY CCR TCA TC-3', PAR-F and PAR-R2 (inner): 5'-GCR TCR TCW GAR TGR TGD GCA A-3', and RES-MOR-HEN-F (outer): 5'-TGG GCW

TAC-3' for the polymerase gene (47). Initial denaturation was performed at $95^{\circ} \mathrm{C}$ for $5 \mathrm{~min}$, followed by 6 cycles of denaturation at $94^{\circ} \mathrm{C}$ for $30 \mathrm{sec}$, annealing at $37^{\circ} \mathrm{C}$ for $30 \mathrm{sec}$, and elongation at $72^{\circ} \mathrm{C}$ for $1 \mathrm{~min}$; followed by 32 cycles of denaturation at $94^{\circ} \mathrm{C}$ for $30 \mathrm{sec}$, annealing at $42^{\circ} \mathrm{C}$ for $30 \mathrm{sec}$, and elongation at $72^{\circ} \mathrm{C}$ for $1 \mathrm{~min}$ (ProFlex PCR System, Life

393 Technology, CA, USA). PCR products were purified using the LaboPass PCR purification kit 
394 (Cosmo Genetech, Seoul, ROK), and sequencing was performed in both directions of each

395 PCR product using a BigDye Terminator v3.1 Cycle Sequencing Kit (Applied Biosystems) on

396 an automated sequencer (ABI 3730XL DNA Analyzer, Applied Biosystems).

\section{Sequence-independent, single-primer amplification}

398 cDNA was generated from total RNA extracted from paramyxovirus-infected cells using

399 FR26RV-N (5'-GCC GGA GCT CTG CAG ATA TCN NNN NN-3'). The reaction was 400 performed in a $20-\mu \mathrm{L}$ reaction mixture containing $7 \mu \mathrm{L}$ total $\mathrm{RNA}, 2 \mu \mathrm{L} 10 \mathrm{pM}$ of primer, 2 $401 \mu \mathrm{L} 5 \times$ First strand buffer, $100 \mathrm{mM}$ dithiothreitol, $25 \mathrm{mM} \mathrm{MgCl} 2,10 \mathrm{mM}$ dNTPs, $0.5 \mu \mathrm{L}$ 402 RNaseOUT, and $0.5 \mu \mathrm{L}$ Superscript III RTase (Life Technologies, Carlsbad, CA, USA) in a 403 Proplex thermocycler (Life Technologies). The PCR conditions were as follows: $25^{\circ} \mathrm{C}$ for 10 $404 \mathrm{~min}, 50^{\circ} \mathrm{C}$ for $50 \mathrm{~min}$, and $85^{\circ} \mathrm{C}$ for $10 \mathrm{~min}$. Double-stranded (ds) cDNA was synthesized using 4050.2 units Klenow $3^{\prime} \rightarrow 5^{\prime}$ 'exo DNA polymerase (Enzynomics, Daejeon, ROK) and $1 \mu \mathrm{L}$ RNaseH 406 (Invitrogen, San Diego, CA). The Klenow reaction mixture was incubated at $37^{\circ} \mathrm{C}$ for $1 \mathrm{hr}$ and $40775^{\circ} \mathrm{C}$ for $15 \mathrm{~min}$. The ds cDNA was purified using the MinElute PCR purification kit (Cat No. 408 28004, Qiagen, Hilden, Germany). Using the FR20RV (5'-GCC GGA GCT CTG CAG ATA 409 TC-3') primer, ds cDNA was amplified in a 50- $\mu \mathrm{L}$ reaction mixture containing $10 \mu \mathrm{L}$ ds cDNA 410 template, $10 \mathrm{pM}$ primer, and $2 \times$ My Taq Red (Bioline, Taunton, MA, USA). The PCR 411 conditions were as follows: initial denaturation at $98^{\circ} \mathrm{C}$ for $30 \mathrm{sec}$, followed by 38 cycles of 412 denaturation at $98^{\circ} \mathrm{C}$ for $10 \mathrm{sec}$, annealing at $54^{\circ} \mathrm{C}$ for $20 \mathrm{sec}$, and elongation at $72^{\circ} \mathrm{C}$ for 45 413 sec.

\section{$414 \quad$ NGS for Illumina MiSeq}

415 We prepared libraries using the TruSeq NAano DNA LT Sample Preparation Kit (Illumina, 416 San Diego, CA, USA) according to the manufacturer's instructions. The samples were 417 mechanically sheared using an M220 focused ultrasonicator (Covaris, Woburn, MA, USA). 418 The cDNA amplicon was size-selected, A-tailed, ligated with indexes and adaptors, and 
enriched. We sequenced libraries using the MiSeq benchtop sequencer (Illumina) with $2 \times 150$ bp and a MiSeq reagent V2 (Illumina).

\section{NGS for Illumina HiSeq}

Total RNA was isolated using the Trizol reagent (AMBION). RNA quality was assessed using an Agilent 2100 bioanalyzer (Agilent Technologies, Amstelveen, The Netherlands), and RNA quantification was performed using the ND-2000 Spectrophotometer (Thermo Fisher Scientific, Waltham, MA, USA). Libraries were prepared from total RNA using the NEBNext Ultra II isolation of mRNA was performed using the Poly(A) RNA Selection Kit (LEXOGEN, Vienna, Austria). The isolated mRNAs were used for cDNA synthesis and shearing, following the manufacturer's instructions. Indexing was performed using Illumina indexes 1-12. The enrichment step was performed using PCR. Subsequently, the libraries were checked using the Agilent 2100 bioanalyzer (DNA High Sensitivity Kit) to evaluate the mean fragment size. sequencing using the HiSeq X10 system (Illumina).

\section{NGS data analysis}

Adaptor and index sequences of reads were trimmed, and low-quality sequences were filtered using the CLC Genomics Workbench version 7.5.2 (CLC Bio, Cambridge, MA). The genome sequences of TaiV, BeiV, JV, MMLPV-1, and -2 were used in a reference mapping method.

439 Read mapping to the reference genome sequence and extraction of consensus sequences were 440 performed, and the genomic sequences of Jeilongvirus were deposited in GenBank (Accession 441 number: MT823459-MT823464). The NGS outputs were analysed using our bioinformatics 442 pipeline. The reads were trimmed with Trimmomatic (v0.36) to remove adapter sequences 443 (48). To exclude the reads from the host genome, they were aligned against the host sequences 
444 using Bowtie2 (v2.2.6), and only unaligned reads were used for the subsequent steps (49).

445 Owing to the absence of the completely sequenced genome of the host species, only the

446 complete mitochondrial sequence of the species on the NCBI RefSeq was used as a host

447 reference (50). The remaining reads were filtered for quality using FaQCs (v0.11.5), and de-

448 novo assembly was performed to produce contigs using SPAdes (v3.11.1) (51, 52). The

449 assembled contigs were subsequently examined in a database consisting of complete viral

450 genomes collected from the NCBI RefSeq database (updated in May 2018) using BLASTn

$451 \quad(\mathrm{v} 2.6 \cdot 0)$.

\section{RACE PCR}

453 To obtain the $3^{\prime}$ and $5^{\prime}$ terminal genome sequences of paramyxovirus, we performed RACE

454 PCR using a SMARTer® RACE 5'/3' Kit (Takara Bio), according to the manufacturer's 455 specifications. We purified the PCR products using the LaboPass PCR Purification Kit (Cosmo

456 Genetech). Sequencing was performed in both directions of each PCR product using the 457 BigDye Terminator v3.1 Cycle Sequencing Kit (Applied Biosystems) on an automated 458 sequencer (Applied Biosystems).

\section{Phylogenetic analysis}

460 The viral genomic sequences were aligned and trimmed using the Clustal $\mathrm{W}$ tool in the 461 Lasergene program version 5 (DNASTAR, USA), and multiple sequence alignment was 462 performed with high accuracy and high throughput MUSCLE algorithms in MEGA 7.0 (53). 463 Phylogenetic trees were constructed using the maximum likelihood method according to the 464 best-fit substitution model. Support for the topologies was assessed using bootstrapping for 4651,000 iterations. In addition, the Bayesian inference method BEAST package (v1.10.4) was 466 used, employing the Markov chain Monte Carlo (MCMC) method (54). The MCMC chain 467 length was set to 100 million states by sampling every 50,000 states. Maximum clade 
credibility trees were extracted using TreeAnnotator (v1.10.4) and prepared using FigTree

469 (v1.4.0).

\section{Analysis of potential NLG sites in the G gene}

471 Full-length amino acid sequences were submitted to the NetNlyc 1.0 (Kemitorvet, Denmark)

472 to predict the NLG sites of the G gene of Jeilongviruses (55).

\section{Domain structural analysis}

474 To find homology, we ran NCBI BLASTP (https://blast.ncbi.nlm.nih.gov/Blast.cgi) using 475 PAPV-1 and -2 G protein sequences against the NR database using default settings. When we 476 ran BLASTP using PAPV-1 G protein and not PAPV-2 G protein, we found the alignments 477 shown in the supplement covering both domains. To detect remote homologs and determine 478 domain architecture, we ran an HHsearch (https://toolkit.tuebingen.mpg.de/tools/hhpred) using 479 PAPV-1 and -2 sequences against PDB, ECOD, and Pfam databases $(56,57)$. To detect the 480 domain boundaries and various sequence and/or structural features including secondary 481 structure and disordered regions, we ran Quick2D 482 (https://toolkit.tuebingen.mpg.de/tools/quick2d) using PAPV-1 G protein as a query. Finally, 483 to confirm the domain architectures in the related $G$ proteins, we ran Promals with default 484 settings (58).

\section{Statistical analysis}

486 Statistical analyses were performed as indicated in each figure using GraphPad Prism version 4875.00 for Windows (GraphPad Software, San Diego, California, USA; www.graphpad.com). 


\section{Acknowledgments and funding sources}

489 We thank Mr. Su-Am Kim for collecting wild rodents. This work was supported by the

490 Research Program To Solve Social Issues of the National Research Foundation of Korea (NRF)

491 funded by the Ministry of Science and Information and Communication Technology (ICT)

492 (NRF-2017M3A9E4061992 and NRF-2019R1I1A2A01060902). In addition, this work was

493 supported by the Agency for Defense Development (UE202026GD). Partial funding was

494 provided by the Armed Forces Health Surveillance Division Global Emerging Infections

495 Surveillance Branch (GEIS), ProMIS ID P0039_18_ME. The views expressed in this article

496 are those of the author and do not necessarily reflect the official policy or position of the

497 Department of the Army, Department of Defense, or the U.S. Government. Authors, as

498 employees of the U.S. Government (TAK, HCK), conducted the work as part of their official

499 duties. Title 17 U.S.C. $\$ 105$ provides that 'Copyright protection under this title is not available

500 for any work of the United States Government.' Title 17 U.S.C. $\$ 101$ defines a U.S.

501 Government work is a work prepared by an employee of the U.S. Government as part of the

502 person's official duties.

503

504 Author Contributions

505 S.H.L., J.S.N. designed study, collected, analyzed, and interpreted data, and wrote the

506 manuscript. K.K. provided scientific discussion and data analyses. B.H.K., S.C. provided

507 scientific discussion. H.C.K., T.A.K. captured small mammals. S.B., K.P., G.Y.L., H.S.C.,

508 S.C., J.W.K., J.G.L., S.H.C. performed experiment and provided scientific discussion and

509 review. C.S.U. provided scientific discussion and review. W.K.K., J.W.S. designed study,

510 analyzed and interpreted data, wrote, reviewed, and revised the manuscript. 
bioRxiv preprint doi: https://doi.org/10.1101/2021.03.03.433816; this version posted March 4, 2021. The copyright holder for this preprint (which was not certified by peer review) is the author/funder. All rights reserved. No reuse allowed without permission.

\section{Competing Interests statement}

513 The authors declare no competing financial interests. 


\section{References}

515 1. Taylor LH, Latham SM, Woolhouse ME. 2001. Risk factors for human disease 516 emergence. Philos Trans R Soc Lond B Biol Sci 356:983-9.

517 2. Woolhouse ME, Gowtage-Sequeria S. 2005. Host range and emerging and reemerging 518 pathogens. Emerg Infect Dis 11:1842-7.

519 3. Johnson CK, Hitchens PL, Pandit PS, Rushmore J, Evans TS, Young CCW, Doyle MM. 2020. Global shifts in mammalian population trends reveal key predictors of virus spillover risk. Proc Biol Sci 287:20192736.

4. Kreuder Johnson C, Hitchens PL, Smiley Evans T, Goldstein T, Thomas K, Clements A, Joly DO, Wolfe ND, Daszak P, Karesh WB, Mazet JK. 2015. Spillover and pandemic properties of zoonotic viruses with high host plasticity. Sci Rep 5:14830.

5. Palmer SR, Soulsby L, Torgerson P, Brown DWG. 2011. Oxford Textbook of ZoonosesBiology, Clinical Practice, and Public Health Control doi:10.1093/med/9780198570028.001.0001. Oxford University Press.

6. Meerburg BG, Singleton GR, Kijlstra A. 2009. Rodent-borne diseases and their risks for public health. Critical Reviews in Microbiology 35:221-270.

530 7. Barzon L, Lavezzo E, Militello V, Toppo S, Palu G. 2011. Applications of nextgeneration sequencing technologies to diagnostic virology. Int J Mol Sci 12:7861-84.

8. Capobianchi MR, Giombini E, Rozera G. 2013. Next-generation sequencing technology in clinical virology. Clin Microbiol Infect 19:15-22.

534 9. Blomstrom AL. 2011. Viral metagenomics as an emerging and powerful tool in veterinary medicine. Vet Q 31:107-14.

10. Belak S, Karlsson OE, Blomstrom AL, Berg M, Granberg F. 2013. New viruses in veterinary medicine, detected by metagenomic approaches. Vet Microbiol 165:95-101. 
538 11. Aguirre de Carcer D, Angly FE, Alcami A. 2014. Evaluation of viral genome assembly and diversity estimation in deep metagenomes. BMC Genomics 15:989.

540 12. Williams SH, Che X, Garcia JA, Klena JD, Lee B, Muller D, Ulrich W, Corrigan RM, Nichol S, Jain K, Lipkin WI. 2018. Viral Diversity of House Mice in New York City.

543 13. Rima B, Balkema-Buschmann A, Dundon WG, Duprex P, Easton A, Fouchier R, Kurath G, Lamb R, Lee B, Rota P, Wang L, Ictv Report C. 2019. ICTV Virus Taxonomy Profile: Paramyxoviridae. J Gen Virol 100:1593-1594.

14. Thibault PA, Watkinson RE, Moreira-Soto A, Drexler JF, Lee B. 2017. Zoonotic Potential of Emerging Paramyxoviruses: Knowns and Unknowns. Advances in Virus Research, Vol 98 98:1-55.

15. Jack PJ, Boyle DB, Eaton BT, Wang LF. 2005. The complete genome sequence of J virus reveals a unique genome structure in the family Paramyxoviridae. J Virol 79:10690-700.

16. Li Z, Yu M, Zhang H, Magoffin DE, Jack PJ, Hyatt A, Wang HY, Wang LF. 2006. Beilong virus, a novel paramyxovirus with the largest genome of non-segmented negative-stranded RNA viruses. Virology 346:219-28.

17. Woo PC, Lau SK, Wong BH, Wong AY, Poon RW, Yuen KY. 2011. Complete genome sequence of a novel paramyxovirus, Tailam virus, discovered in Sikkim rats. J Virol 85:13473-4.

18. Vanmechelen B, Bletsa M, Laenen L, Lopes AR, Vergote V, Beller L, Deboutte W, Korva M, Avsic Zupanc T, Gouy de Bellocq J, Gryseels S, Leirs H, Lemey P, Vrancken

B, Maes P. 2018. Discovery and genome characterization of three new Jeilongviruses, a lineage of paramyxoviruses characterized by their unique membrane proteins. BMC Genomics 19:617. 
563 19. Jun MH, Karabatsos N, Johnson RH. 1977. A new mouse paramyxovirus (J virus). Aust J Exp Biol Med Sci 55:645-7.

565

20. Woo PCY, Lau SKP, Wong BHL, Wu Y, Lam CSF, Yuen KY. 2012. Novel Variant of Beilong Paramyxovirus in Rats, China. Emerging Infectious Diseases 18:1022-1024.

21. Bao X, Kolli D, Liu T, Shan Y, Garofalo RP, Casola A. 2008. Human metapneumovirus small hydrophobic protein inhibits NF-kappaB transcriptional activity. J Virol 82:82249.

22. Abraham M, Arroyo-Diaz NM, Li Z, Zengel J, Sakamoto K, He B. 2018. Role of Small Hydrophobic Protein of J Paramyxovirus in Virulence. J Virol 92.

23. Li Z, Xu J, Patel J, Fuentes S, Lin Y, Anderson D, Sakamoto K, Wang LF, He B. 2011. Function of the small hydrophobic protein of J paramyxovirus. J Virol 85:32-42.

24. Li Z, Xu J, Chen Z, Gao X, Wang LF, Basler C, Sakamoto K, He B. 2013. The L gene of J paramyxovirus plays a critical role in viral pathogenesis. J Virol 87:12990-8.

25. Drexler JF, Corman VM, Muller MA, Maganga GD, Vallo P, Binger T, Gloza-Rausch F, Cottontail VM, Rasche A, Yordanov S, Seebens A, Knornschild M, Oppong S, Adu Sarkodie Y, Pongombo C, Lukashev AN, Schmidt-Chanasit J, Stocker A, Carneiro AJ, Erbar S, Maisner A, Fronhoffs F, Buettner R, Kalko EK, Kruppa T, Franke CR, Kallies

26. Alkhovsky S, Butenko A, Eremyan A, Shchetinin A. 2018. Genetic characterization of RG, Leroy EM, Drosten C. 2012. Bats host major mammalian paramyxoviruses. Nat bank vole virus (BaVV), a new paramyxovirus isolated from kidneys of bank voles in Russia. Arch Virol 163:755-759.

27. Samal SK. 2008. Paramyxoviruses of Animals. Encyclopedia of Virology doi:10.1016/B978-012374410-4.00460-X:40-47. 
28. Masante C, El Najjar F, Chang A, Jones A, Moncman CL, Dutch RE. 2014. The human metapneumovirus small hydrophobic protein has properties consistent with those of a viroporin and can modulate viral fusogenic activity. J Virol 88:6423-33.

29. El Najjar F, Schmitt AP, Dutch RE. 2014. Paramyxovirus glycoprotein incorporation, assembly and budding: a three way dance for infectious particle production. Viruses 6:3019-3054.

30. Navaratnarajah CK, Generous AR, Yousaf I, Cattaneo R. 2020. Receptor-mediated cell entry of paramyxoviruses: Mechanisms, and consequences for tropism and pathogenesis. The Journal of biological chemistry 295:2771-2786.

31. Ader N, Brindley MA, Avila M, Origgi FC, Langedijk JP, Orvell C, Vandevelde M, Zurbriggen A, Plemper RK, Plattet P. 2012. Structural rearrangements of the central region of the morbillivirus attachment protein stalk domain trigger $\mathrm{F}$ protein refolding for membrane fusion. J Biol Chem 287:16324-34.

33. Ader-Ebert N, Khosravi M, Herren M, Avila M, Alves L, Bringolf F, Orvell C, changes in the morbillivirus attachment protein initiate the membrane fusion process. PLoS Pathog 11:e1004880.

34. Bishop KA, Hickey AC, Khetawat D, Patch JR, Bossart KN, Zhu Z, Wang LF, 
613 35. Bose S, Song AS, Jardetzky TS, Lamb RA. 2014. Fusion Activation through

614

615

616

617

618

619

620

621

622

623

624

625

626

627

628

629

630

631

632

633

634

635

636

Attachment Protein Stalk Domains Indicates a Conserved Core Mechanism of Paramyxovirus Entry into Cells. Journal of Virology 88:3925-3941.

36. Bose S, Jardetzky TS, Lamb RA. 2015. Timing is everything: Fine-tuned molecular machines orchestrate paramyxovirus entry. Virology 479-480:518-31.

37. Mishra PM, Verma NC, Rao C, Uversky VN, Nandi CK. 2020. Intrinsically disordered proteins of viruses: Involvement in the mechanism of cell regulation and pathogenesis. Progress in molecular biology and translational science 174:1-78.

38. Giri R, Kumar D, Sharma N, Uversky VN. 2016. Intrinsically Disordered Side of the Zika Virus Proteome. Front Cell Infect Microbiol 6:144.

39. Biering SB, Huang A, Vu AT, Robinson LR, Bradel-Tretheway B, Choi E, Lee B, Aguilar HC. 2012. N-Glycans on the Nipah virus attachment glycoprotein modulate fusion and viral entry as they protect against antibody neutralization. J Virol 86:119912002.

40. Sagar M, Wu X, Lee S, Overbaugh J. 2006. Human immunodeficiency virus type 1 V1V2 envelope loop sequences expand and add glycosylation sites over the course of infection, and these modifications affect antibody neutralization sensitivity. J Virol 80:9586-98.

41. Wolk T, Schreiber M. 2006. N-Glycans in the gp120 V1/V2 domain of the HIV-1 strain NL4-3 are indispensable for viral infectivity and resistance against antibody neutralization. Med Microbiol Immunol 195:165-72.

42. Wei X, Decker JM, Wang S, Hui H, Kappes JC, Wu X, Salazar-Gonzalez JF, Salazar MG, Kilby JM, Saag MS, Komarova NL, Nowak MA, Hahn BH, Kwong PD, Shaw GM. 2003. Antibody neutralization and escape by HIV-1. Nature 422:307-12. 
637 43. Aguilar HC, Matreyek KA, Filone CM, Hashimi ST, Levroney EL, Negrete OA, Bertolotti-Ciarlet A, Choi DY, McHardy I, Fulcher JA, Su SV, Wolf MC, Kohatsu L, Baum LG, Lee B. 2006. N-glycans on Nipah virus fusion protein protect against neutralization but reduce membrane fusion and viral entry. J Virol 80:4878-89.

641

44. Tripp RA, Oshansky C, Alvarez R. 2005. Cytokines and respiratory syncytial virus infection. Proc Am Thorac Soc 2:147-9.

45. Eaton BT, Broder CC, Middleton D, Wang LF. 2006. Hendra and Nipah viruses: different and dangerous. Nat Rev Microbiol 4:23-35.

46. Tapia K, Kim WK, Sun Y, Mercado-Lopez X, Dunay E, Wise M, Adu M, Lopez CB. 2013. Defective viral genomes arising in vivo provide critical danger signals for the triggering of lung antiviral immunity. PLoS Pathog 9:e1003703.

47. Tong S, Chern SWW, Li Y, Pallansch MA, Anderson LJ. 2008. Sensitive and broadly reactive reverse transcription-PCR assays to detect novel paramyxoviruses. Journal of Clinical Microbiology 46:2652-2658.

48. Bolger AM, Lohse M, Usadel B. 2014. Trimmomatic: a flexible trimmer for Illumina sequence data. Bioinformatics 30:2114-20.

49. Langmead B, Salzberg SL. 2012. Fast gapped-read alignment with Bowtie 2. Nat Methods 9:357-9.

50. Pruitt KD, Tatusova T, Maglott DR. 2007. NCBI reference sequences (RefSeq): a curated non-redundant sequence database of genomes, transcripts and proteins. Nucleic Acids Res 35:D61-5.

51. Lo CC, Chain PS. 2014. Rapid evaluation and quality control of next generation sequencing data with FaQCs. BMC Bioinformatics 15:366.

660 52. Bankevich A, Nurk S, Antipov D, Gurevich AA, Dvorkin M, Kulikov AS, Lesin VM, 661 Nikolenko SI, Pham S, Prjibelski AD, Pyshkin AV, Sirotkin AV, Vyahhi N, Tesler G, 
Alekseyev MA, Pevzner PA. 2012. SPAdes: a new genome assembly algorithm and its applications to single-cell sequencing. J Comput Biol 19:455-77.

664

53. Kumar S, Stecher G, Tamura

K. 2016. MEGA7: Molecular Evolutionary Genetics Analysis Version 7.0 for Bigger Datasets. Molecular Biology and Evolution 33:1870-

666 1874.

667

54. Suchard MA, Lemey P, Baele G, Ayres DL, Drummond AJ, Rambaut A. 2018. Bayesian phylogenetic and phylodynamic data integration using BEAST 1.10. Virus Evol 4:vey016.

55. Gavel Y, von Heijne G. 1990. Sequence differences between glycosylated and nonglycosylated Asn-X-Thr/Ser acceptor sites: implications for protein engineering. Protein Eng 3:433-42.

56. Zimmermann L, Stephens A, Nam S-Z, Rau D, Kübler J, Lozajic M, Gabler F, Söding J, Lupas AN, Alva V. 2018. A Completely Reimplemented MPI Bioinformatics Toolkit with a New HHpred Server at its Core. Journal of Molecular Biology 430:2237-2243.

676 57. Steinegger M, Meier M, Mirdita M, Vöhringer H, Haunsberger SJ, Söding J. 2019. HHsuite3 for fast remote homology detection and deep protein annotation. BMC Bioinformatics 20:473. of distantly related proteins. Bioinformatics 23:802-8. 
682 Figure 1. An electron microscopic image and the plaque assay of Paju Apodemus paramyxovirus 1 (PAPV-1)

684 (A) PAPV-1 was imaged using transmission electron microscopy (TEM). (B) Photograph of a 685 representative plaque assay plate of PAPV-1 inoculated into Vero E6 cells at 5 days post686 infection. This single plate represents dilutions (from top-left to right: undiluted and dilutions 687 at $1: 10^{1}, 1: 10^{2}$, and bottom-left to right: dilutions at $1: 10^{3}, 1: 10^{4}, 1: 10^{5}$ ) of the virus that mostly 688 destroys the cell monolayer, producing the appropriate number of plaques to count.

689 Figure 2. Organization of the genomes of Paju Apodemus paramyxoviruses 1 and 2

690 The genomic configurations of different paramyxoviruses are shown. The genome of 691 paramyxovirus constitutes 8 to 9 coding regions, 3' NP-C-P-M-F-SH-TM-G-HN-H-L 5'. The color boxes represent coding regions for each gene; N, yellow; $\mathrm{C}$, sky blue; P, blue; $\mathrm{M}$, viridian;

693 F, green; SH, yellow green; TM, orange; G, red; HN, light yellow; H, Chilean pink, and L, 694 purple. The genome size scale is provided at the bottom. Adobe Illustrator CS6 695 (http://www.adobe.com/products/illustrator.html) was used to construct the figures.

696 Figure 3. Phylogenetic tree constructed based on the whole-genome sequences of Paju Apodemus paramyxoviruses and other paramyxoviruses

698 Phylogenetic analysis based on the whole-genome sequences of the Paju Apodemus 699 paramyxoviruses. Evolutionary relationships were inferred using BEAST (v1.10.4) with 700 default priors and assuming homochromous tips. The Markov chain Monte Carlo analysis 701 was performed until adequate sample sizes (ESS > 200) were obtained, and TreeAnnotator 702 (v2.5.4) was used to summarize the maximum clade credibility tree from the posterior tree 703 distribution, using a 10\% burn-in. Paramyxoviridae strains served as reference sequences for 704 the phylogenetic analysis. Red color indicates PAPV-1, and blue indicates PAPV-2. 
705 Figure 4. Replication of PAPV-1 and the induction of innate antiviral genes in human epithelial cell (A549)

707 A549 cells were infected with a multiplicity of infection of 0.02 of PAPV-1. Total RNA was

708 analysed via qRT-PCR and examined for the expression of (A) PAPV-1 RdRp gene, (B) Ifn $\beta$,

709 (C) Ifnl1/Il-29, (D) ISG15, (E) Ifit2/Isg54, (F) Ifit1/Isg56, (G) Rsad2/Viperin, (H) OAS1, (I)

710 Ddx58/Rig-I, (J) Ifihl/Mda5, and (K) Il-6 at 1, 3, 5, and 7 days post-infection. Error bars

711 indicate the standard deviation of triplicate measurements in a representative experiment.

$712 \quad(* \mathrm{p}<0.05 ; * * * \mathrm{p}<0.001$, unpaired student $\mathrm{t}-\mathrm{test}$; ns: non-significant $)$.

713 Figure 5. Replication of PAPV-1 and the induction of innate antiviral genes in human

714 endothelial cells (HUVEC)

715 HUVECs were infected with a multiplicity of infection of 0.02 of PAPV-1. Total RNA was

716 analysed via qRT-PCR and examined for the expression of (A) PAPV-1 RdRp gene, (C)

717 Ifnl1/Il-29, (D) ISG15, (E) Ifit2/Isg54, (F) Ifit1/Isg56, (G) Rsad2/Viperin, (H) OAS1, (I)

718 Ddx58/Rig-I, (J) Ifih1/Mda5, and (K) Il-6 at 1, 3, 5, and 7 days post-infection. Error bars

719 indicate the standard deviation of triplicate measurements in a representative experiment.

$720 \quad(* \mathrm{p}<0.05 ; * * * \mathrm{p}<0.001$, unpaired student $\mathrm{t}$-test; ns: non-significant $)$. 
721 Table

722 Table 1. Prevalence of paramyxovirus infection based on Paju Apodemus

723 paramyxoviruses (PAPVs) captured from 2016 to 2018 in the Republic of Korea

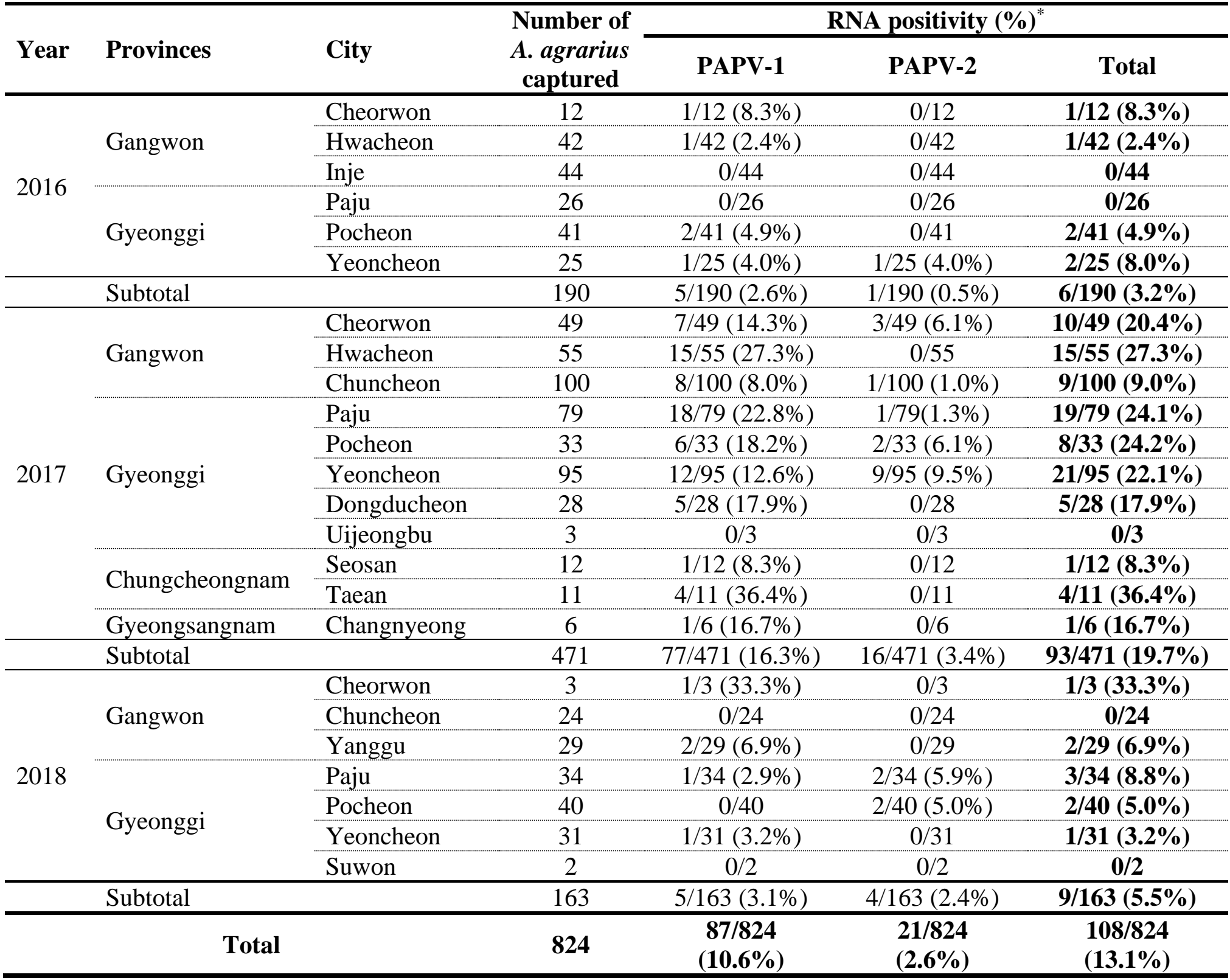

724 "The positive rate of PAPV RNA indicates the detection of the partial L segment, targeting

725 pan-Orthoparamyxovirinae and/or the genera Respirovirus, Morbillivirus, and Henipavirus

726 using RT-PCR and Sanger sequencing. 


\section{Figures}

$737 \quad$ Figure 1.

A

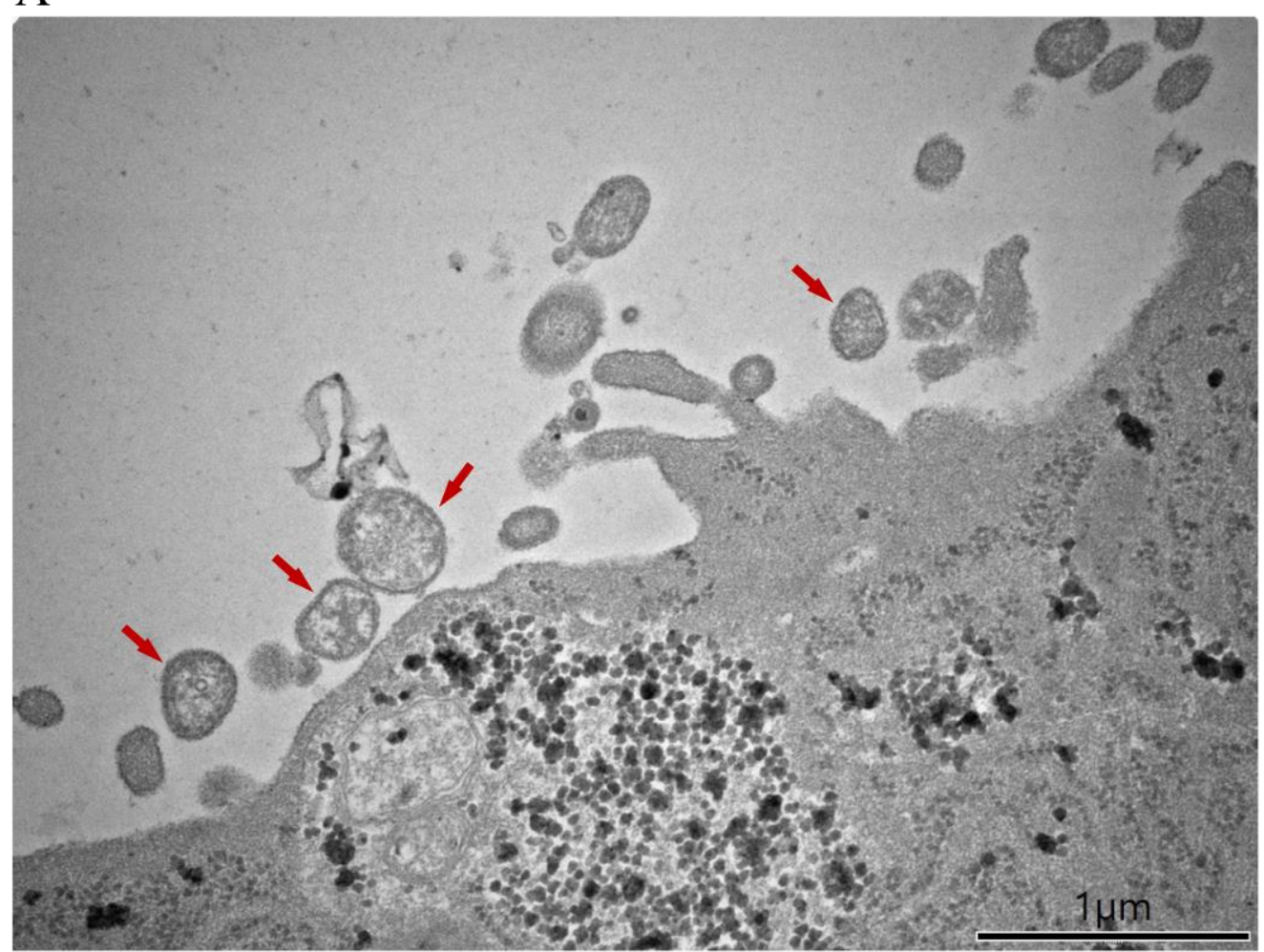

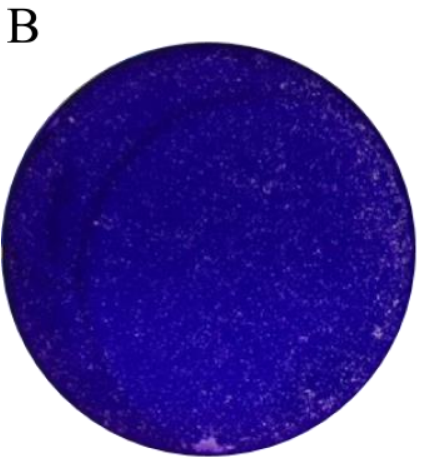

$10^{-1}$

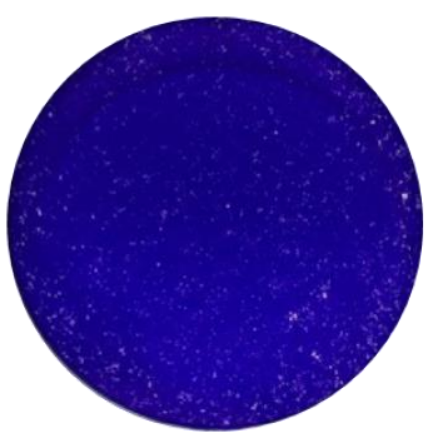

$10^{-2}$

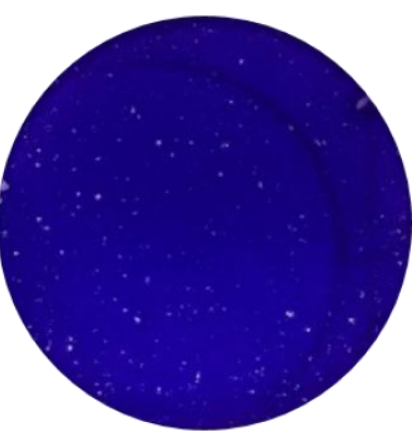

$10^{-3}$

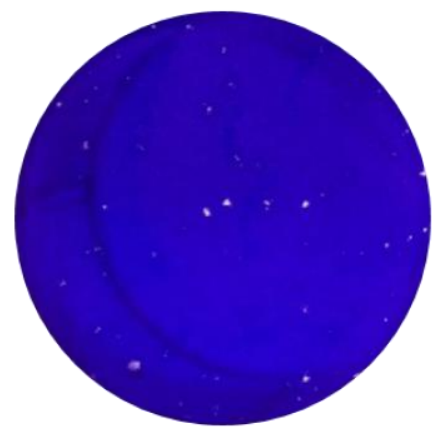

$10^{-4}$

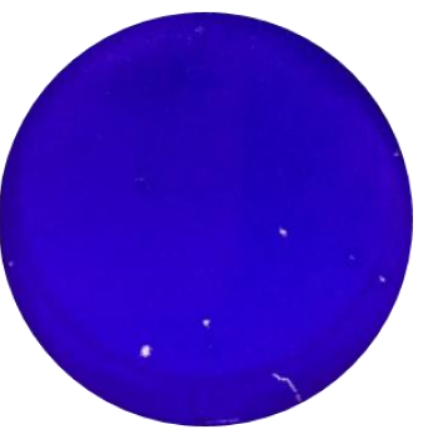

$10^{-5}$ 
739 Figure 2.

Leader $\mathrm{SH}$
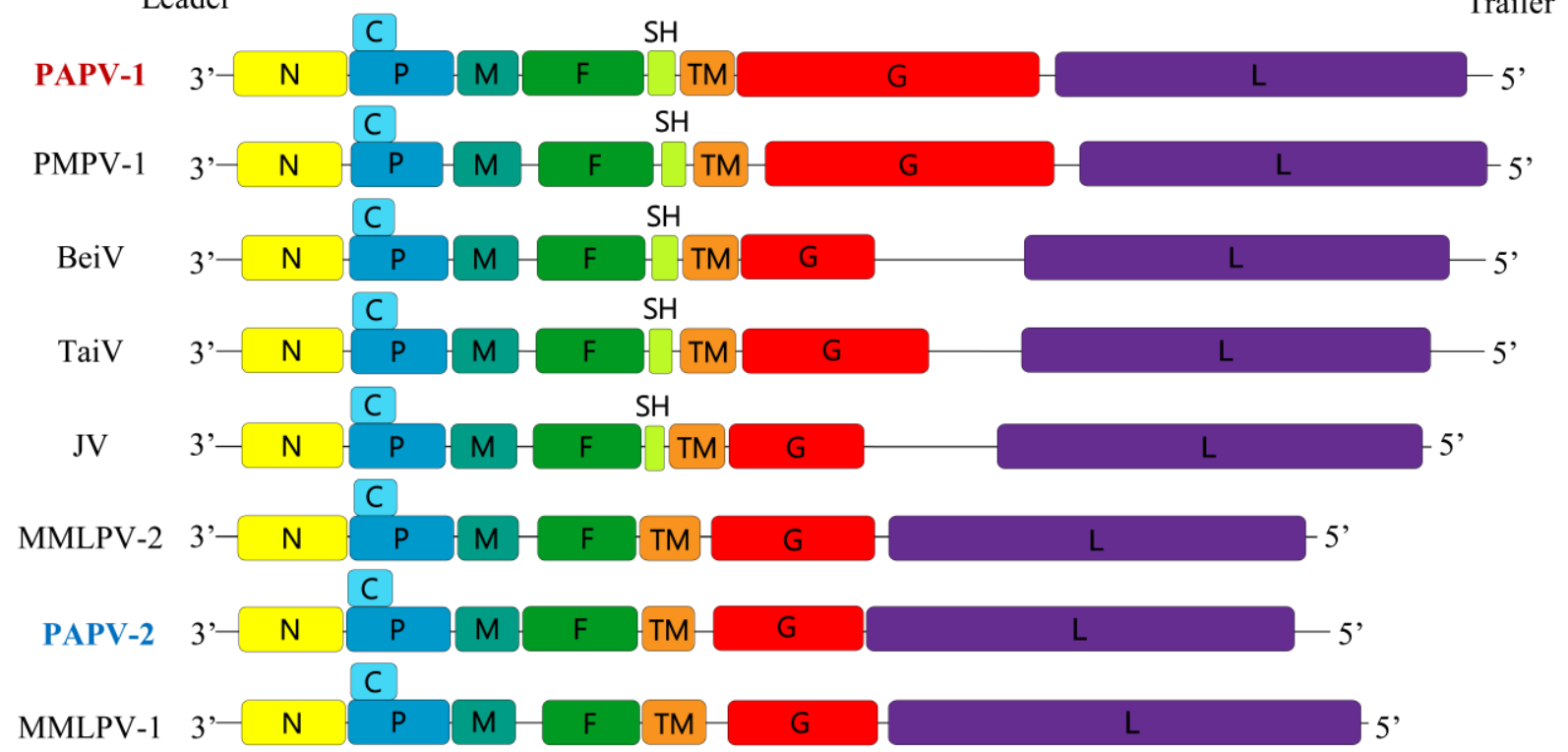

C
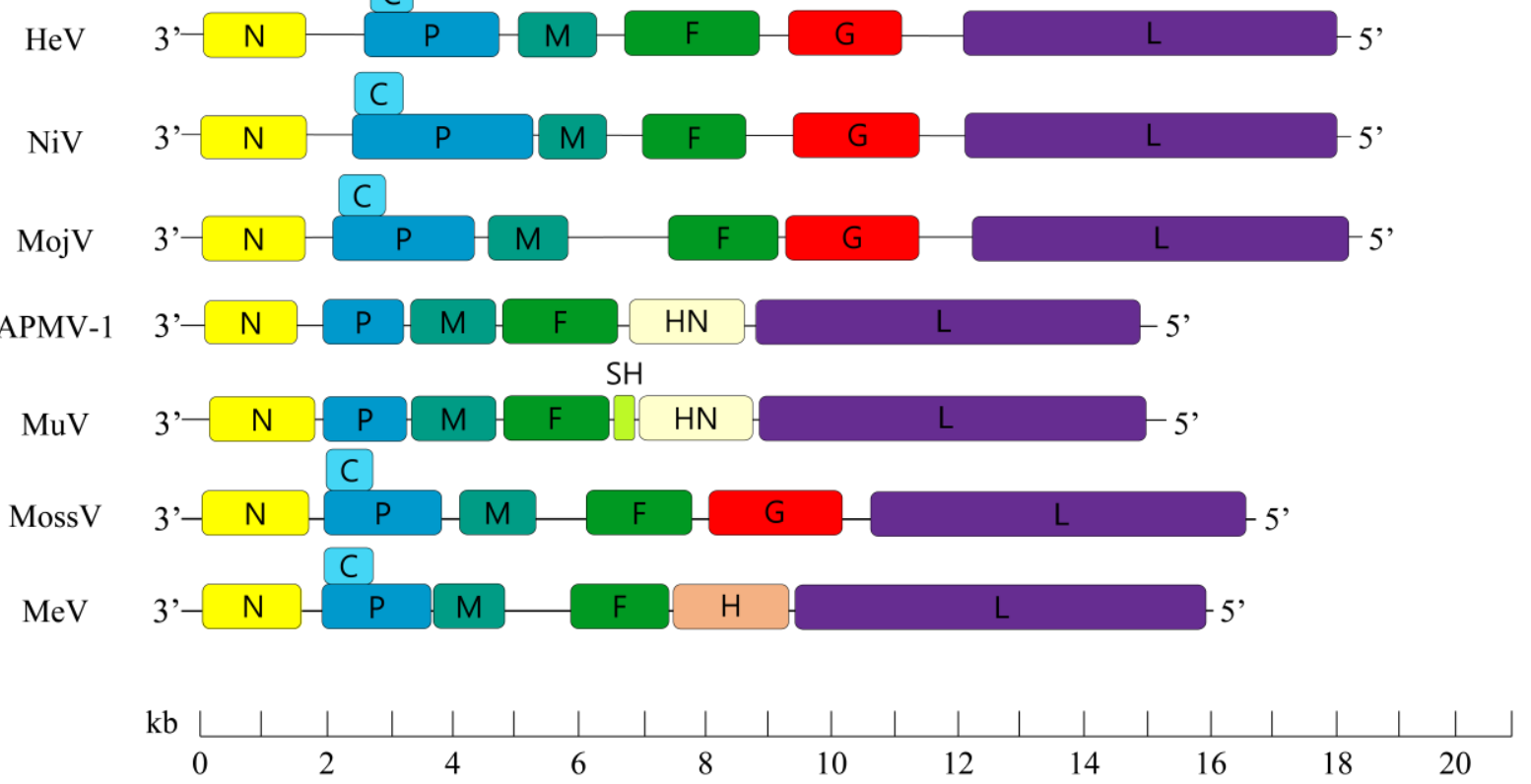


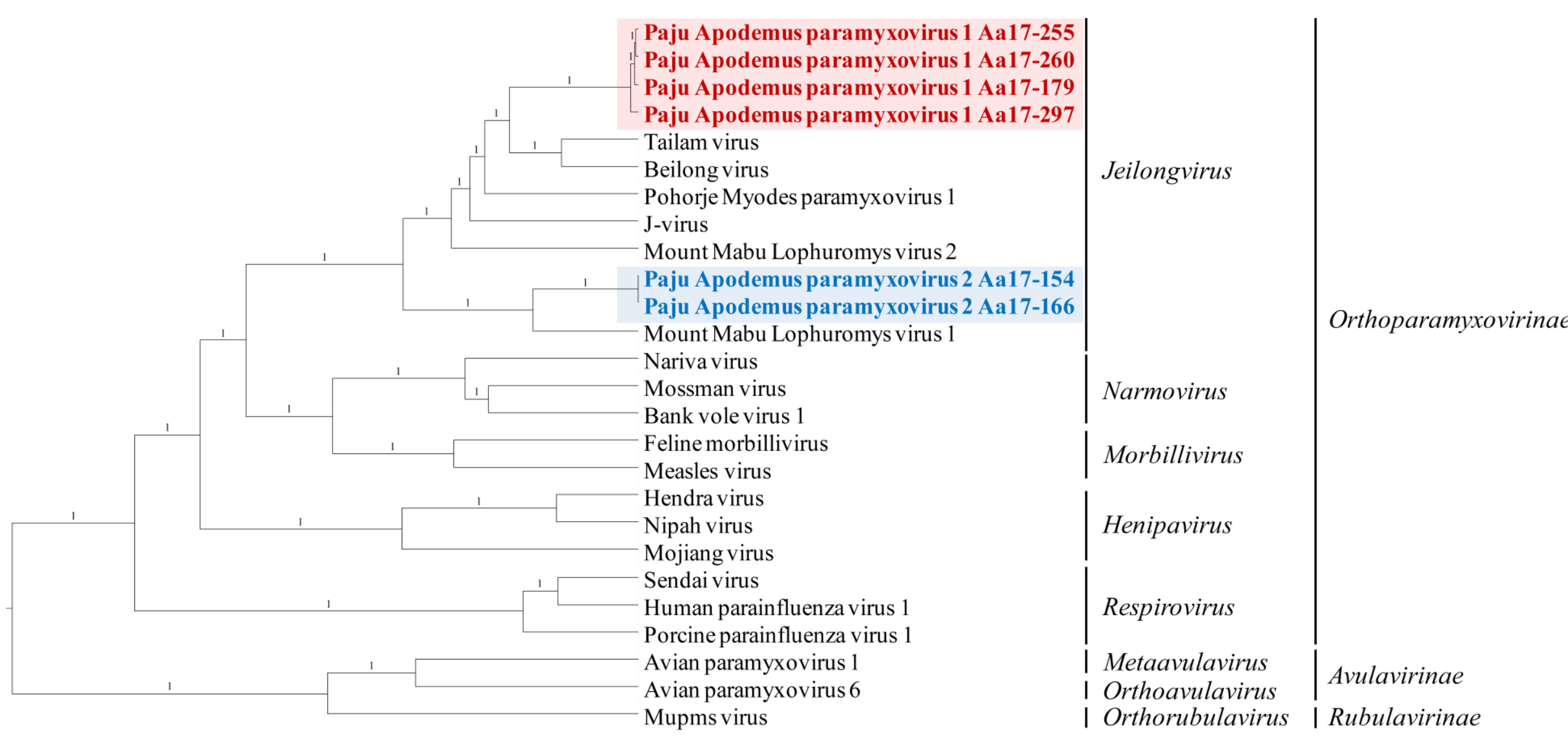




\section{$750 \quad$ Figure 4.}

751
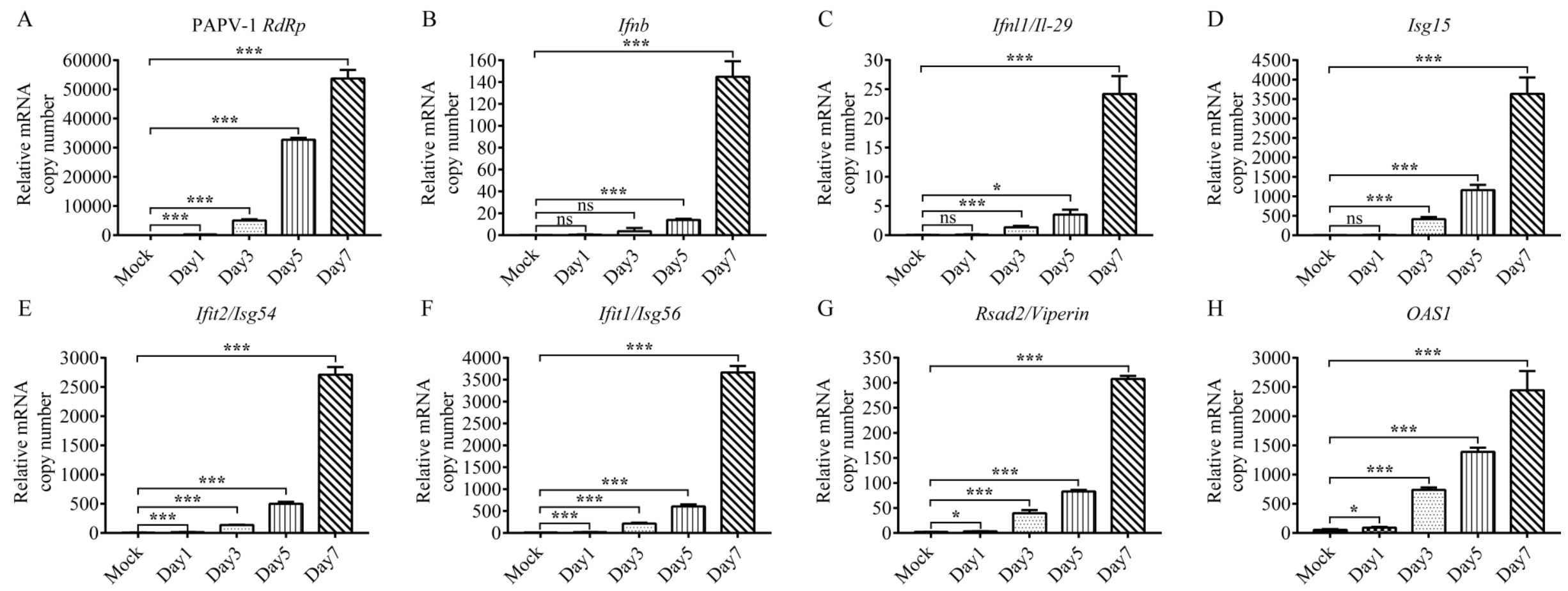

F

G

Rsad2/Viperin

H

OAS1
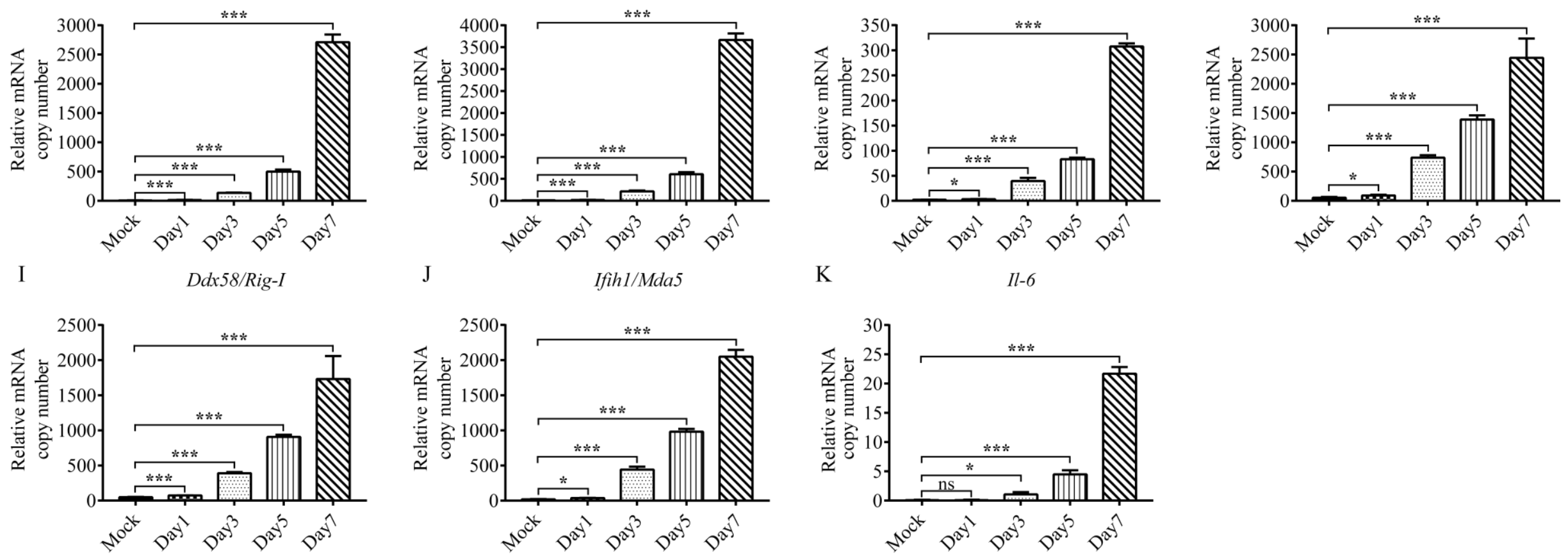
Figure 5.
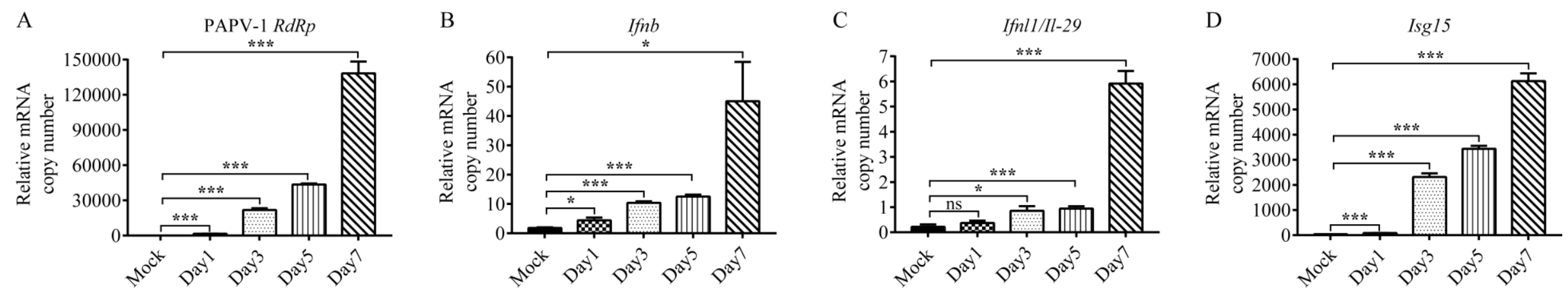

E

F

G

Rsad2/Viperin
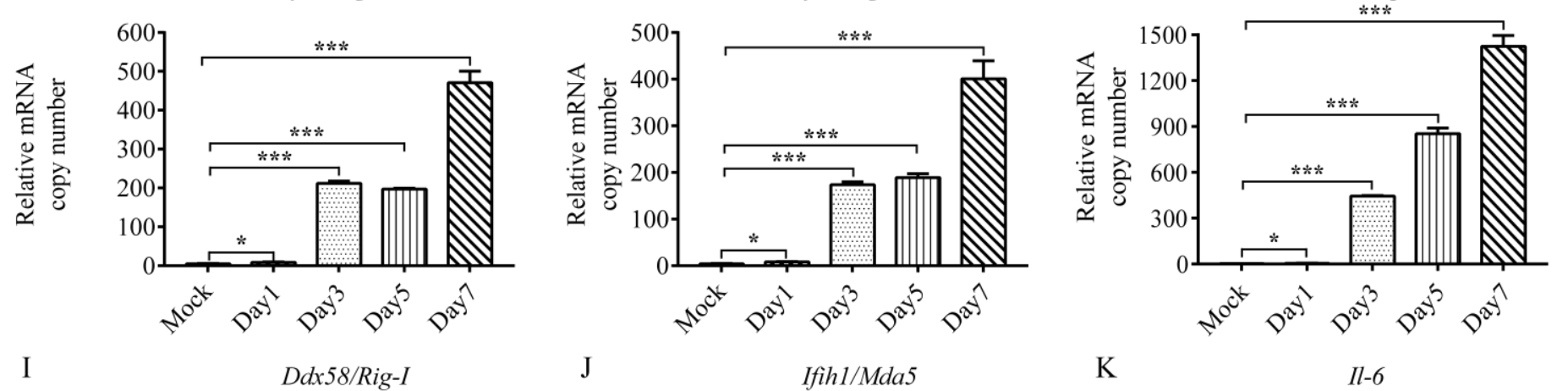

H

OASI
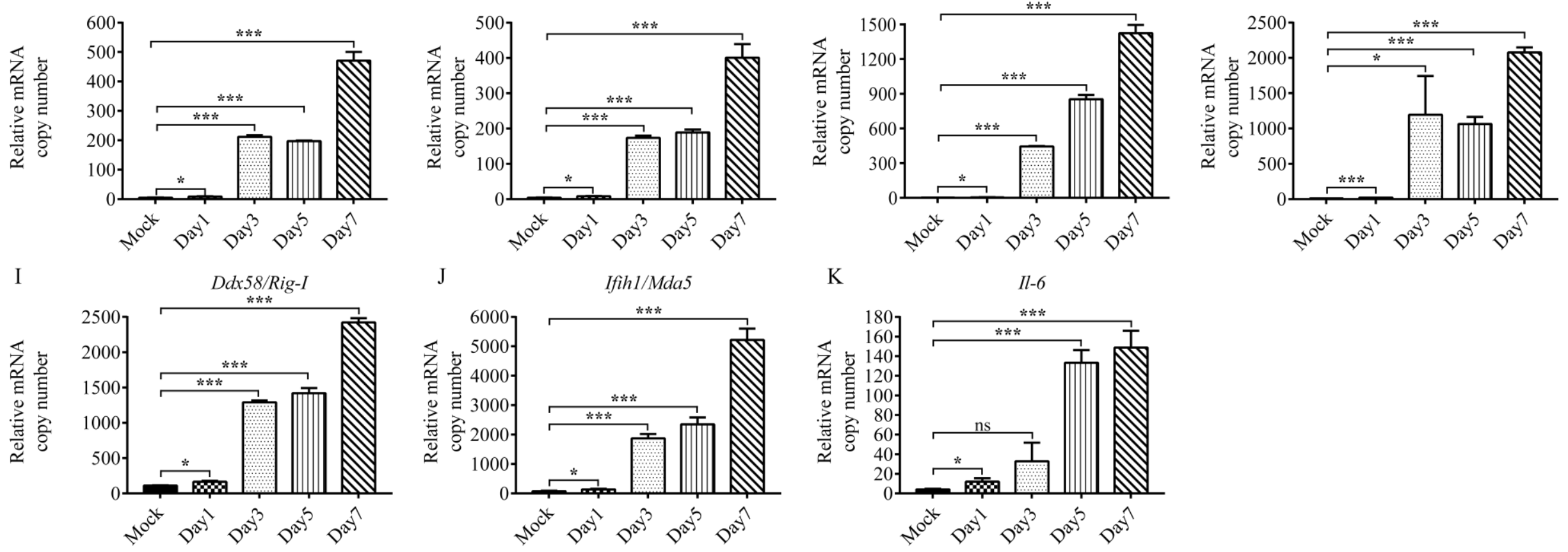